\title{
Evaluation of Quality of Family Medicine Education for Fourth Year Students at the Faculty of Medicine, Suez Canal University, Ismailia, Egypt: Students' Perspectives
}

\section{Sarah Abdel Aaty Abdel Razeq}

Suez Canal University Faculty of Medicine

Hazem Ahmed Sayed Ahmed ( $\sim$ hazemelgamal@yahoo.com )

Suez Canal University Faculty of Medicine https://orcid.org/0000-0002-4922-8706

Hebatallah Nour-eldein

Suez Canal University Faculty of Medicine

\section{Research article}

Keywords: Family Medicine, Learning experiences, Perceptions, Rotations, Satisfaction, Teaching and learning, Undergraduate, Teaching quality

Posted Date: July 9th, 2019

DOl: https://doi.org/10.21203/rs.2.11108/v1

License: (c) (1) This work is licensed under a Creative Commons Attribution 4.0 International License.

Read Full License 


\section{Abstract}

Background Despite delivering high quality of undergraduate family medicine (FM) education positively impacts undergraduates. Egyptian studies of undergraduates' teaching quality in FM are limited. This study aimed to evaluate the fourth year medical students' perspectives on quality of FM education and to determine their learning experiences' associated factors at the Faculty of Medicine, Suez Canal University (FOM/SCU). Methods A cross-sectional study included convenience sampling of 109 participants with a response rate $90.83 \%$ in academic year $2017 / 2018$. Data was collected via emails from August to September 2018 using a self-administrated questionnaire, which included demographic and academic data, Undergraduate Module Experience Questionnaire, and 2 open-ended questions. Results The mean age of participants was $21.93 \pm 0.52$ years and $66 \%$ of participants were females. More than half of participants positively perceived (Mean score was $\geq 4$ ) improving their competencies by attending training in primary healthcare settings (55\%), improving their consultation and communication skills (52.3\%), wide covering of intended learning objectives in assessment $(52.3 \%)$ and satisfaction with objective structured clinical examination (57.8\%). Overload work was perceived (Mean score was 2.97) and others learning experiences subscales were questionable perceived (Mean score was 3-3.99). Participants' perceived the presence of unwanted academic pressure on them, too many topics of syllabus, the unsatisfying of library resources for their needs and unhelpful portfolio guide (Mean score was $<3$ ). Family medicine module satisfied $47.7 \%$ of participants. The predictors of their satisfaction were learning resources (odds $=9.63$ ) and good teaching (odds $=7.624$ ). There was no significant association between students' demographic and academic variables and their perspectives with quality of FM module. Participants suggested more live lectures (37.6\%). Conclusions: Undergraduate FM education strove to satisfy students. Learning resources and good teaching were predictors of their teaching quality. Continuous quality improvement of FM education using students' learning perspectives is needed.

\section{Background}

Family Medicine department (FMD) affiliated to FOM/SCU was established in 1979 to become the first academic FMD in Egypt. It was formerly named department of general practice. Delivering high quality of FM education for undergraduates and continuous improvement of this issue are priorities in FMD and FOM/SCU [1].

It is not easy to define quality of undergraduate teaching and training at the medical schools. Teaching quality can be defined as meeting the prescribed external agencies' standards, or exceeding stakeholders' expectations [2]. Students' learning experiences' measure is an antecedent variable and is considered one of the prominent performance indicators that had been widely used in assessing teaching quality in universities [3]. Undergraduates' satisfaction is the most studied outcome variable of perceived teaching quality in FM $[4,5]$. 
Delivery of high quality FM clerkships for undergraduates has positive impact on them. Systematic review revealed that undergraduates reported satisfaction with teaching and training in FM clerkships, positive attitudes towards FM, enhancement of their previous learning experiences, and improvement of their knowledge and skills on patients' holistic assessment, communication, problem-solving skills, health maintenance for different age groups, disease prevention, and dealing with common acute and chronic conditions [4].

A cross-sectional study was carried out to assess satisfaction with overall clinical education and FM module among final year medical students in the academic year 2014/2015 at the FOM/SCU. It revealed that FM module intellectually stimulated $38.2 \%$ of them and $47.8 \%$ of students become interested in FM. Students' perceptions towards learning experiences e.g. overall satisfaction, generic skills, assessment methods and relevant learning resources to the FOM/SCU were not assessed in this study [5].

A web-based survey carried out among 600 medical students from seven Egyptian medical schools to assess perceptions towards FM and explore associations between different factors, including the study of undergraduate FM curriculum, and their career preferences, but a lot of student's learning experiences were out scope of that study [6].

Undergraduate FM education is integrated with basic and clinical departments in a single undergraduate educational program at the FOM/SCU. It is delivered in the 3 educational phases, the first phase, prepathogenesis phase, includes year 1, the second phase, pathogenesis phase, includes years 2 and 3 . The third phase, clinical clerkship phase, includes years 4-6. Others innovative educational strategies are adopted also e.g. community-oriented and community-based education (CBE), problem-based learning (PBL), and student-centered education and evidence-based medicine $[1,7]$.

Family medicine training and its clinical assessment for undergraduates at the FOM/SCU are carried out in the primary health care (PHC) facilities affiliated to the Ministry of Health and Population (MOHP) from first year to fourth year and final year medical students also are assessed in individual care in PHC. Fourth year medical students receive primary care course, which is integrated course between FM, pediatrics, gynecology, community medicine modules (rounds). The intended learning outcomes (ILOs) of FM for the fourth year are updated every 2 years and were approved by the curriculum committee.

The fourth year medical students had received field training in FM on child and woman health cares, one day per week for 14 weeks at El Shohda, El Sabaa Banat, and Al Sheikh Zayed PHC settings in Ismailia governorate and also at Al Kuwait, Omar Ibn Al Khattab and Al Arab PHC settings in Port Said governorate. Each clinical training session lasted 4 hours (9 a.m. -1 p.m.). During the beginning of second term, field training was ended in Port Said governorate as infrastructures of all PHC settings were maintained for preparation of universal health coverage program.

They also received eLearning in FM. Fourth year students' assessment included portfolio, clinical exam on real PHC patients/attendee, objective structured clinical examination (OSCE), modified essay questions (MEQs) and multiple choice questions (MCQs). 
In the light of the importance of undergraduate FM education in addition to the limited studies in assessment of its quality in Egypt, this study was carried out to evaluate the fourth year medical students' perspectives on quality FM education at the FOM/SCU in the academic year 2017/2018 and to determine the associated factors of students' learning experiences in FM module.

\section{Methods}

\section{Type, Setting and Time of the study:}

A cross-sectional analytical study was carried out at the FOM/SCU; Ismailia, Egypt. Questionnaires were collected from students from August to September 2018.

\section{Study Population and Sampling:}

Convenience sampling of 109 fourth year medical students affiliated to the FOM/SCU in the educational year 2017/2018 were recruited (the response rate was 90.83\%), who accepted to participate in the study. The study excluded students who were not attending the formal assessment in FM module due to unacceptable attendance rate of field training ( $<75 \%$, according to the regulations of FOM/SCU) or any others personal reasons.

\section{Tool of the Study:}

The questionnaire was designed by the research team based on relevant literature [8,9]. The questionnaire was sent to the students via emails. The estimated time for completion of the questionnaire was 20 to 30 minutes. This self-administrated questionnaire consisted of 3 parts: socio-demographic data of the participants, Undergraduate Module Experience Questionnaire (UMEQ), and 2 open-ended questions.

Socio-demographic data of the participants included age in years, gender, marital status, field training PHC center/unit, perceived family income, and last academic degree.

Undergraduate Module Experience Questionnaire was based on the course experience questionnaire (CEQ) $[8,9]$ with some modifications such as assessment and learning resources subscales. The appropriate assessment subscale and some items of learning resources e.g. field training and portfolio guide within UMEQ were developed by the research team to be relevant to the educational process at FOM/SCU.

It was assessed by 32-Likert items, which were arranged in a five-point Likert scale with options of "strongly disagree," "disagree," "no opinion," "agree" and "strongly agree." It consisted of 8 subscales. It included 6 items with reverse codes. The 32 (UMEQ) items were grouped into 8 subscales for analysis purposes: clear outcomes and standards, good teaching, appropriate work load, appropriate assessment, generic skills, intellectual motivation, learning resources, and satisfaction with module. 
Each question on the UMEQ was answered using a 5-point Likert scale ranging from a score of one, where students reported that they strongly disagreed with the statement, to a score of 5 , where they reported that they strongly agreed with the statement. Each response for reverse-coded Likert items was re-coded and scored on a scale of 5 (strongly disagree) to 1 (strongly agree).

The mean score was calculated to every item and the agreeable (positive) perception cut point for every item was $\geq 4$, if the item's mean score is $3-3.99$, this was questionable perception, and if the mean score of item was below 3 , it was not acceptable (negative) perception and need change. For each subscale, the total mean score of all items was calculated then divided by the number of its items to arrive at a summary mean subscale score. Subscales with mean scores $\geq 4,3-3.99$ and $<3$, were agreeable, questionable and unacceptable perceptions, respectively.

Validity was assessed by three experts in FM who gave their judgment on the appropriateness of questionnaire items. For the reliability of the questionnaire, a pilot study included 20 participants from fifth year medical student affiliated to the FOM/SCU of the educational year 2017/2018. This pilot study tested the UMEQ's reliability and assessed the understandability of its items, clearness, acceptability and meaning to subjects.

Cronbach's alpha was used as an internal consistency estimate of the UMEQ's reliability (0.865). Cronbach's alpha values for UMEQ's subscales were $0.697,0.686,0.807,0.714,0.646,0.612,0.705$ and 0.690 for clear outcomes and standards, good teaching, appropriate work load, appropriate assessment, generic skills, intellectual motivation, learning resources, and satisfaction, respectively.

The 2 open-ended questions were "What did you like about this module?" and "What are your suggestions for improving quality of FM education?"

\section{Statistical analysis}

Data was analyzed by SPSS (statistical package for social sciences) version 24. Chronbach's alpha was used as an internal consistency estimate of the reliability of UMEQ and its subscales.

The Mann Whitney $U$ test was used to assess associations between participants' perceptions on learning experiences and their demographic data (e.g. gender and perceived family income). The Kruskal Wallis test was used to assess associations between participants' perceptions on learning experiences and their academic data (e.g. last academic degree and field training center/unit). P-values $<0.05$ are considered significant.

Spearman's rho test was used to assess correlation between UMEQ subscales. Correlation is significant at 0.05 (2-tailed). To estimate the learning experiences' predictors of participants' satisfaction (dependent variable), binary logistic regression analysis was performed. P-values $<0.05$ are considered significant.

\section{Results}


The study included 109 fourth year medical students, affiliated to FOM/SCU (90.83\% of the total target population). The mean age of the students was $21.93 \pm 0.52$ years and $66 \%$ of participants were females as shown in table 1 . More than two-thirds $(67.89 \%)$ of participants were trained in PHC settings affiliated to MOHP in Ismailia governorate.

Table 2 shows that participants reported questionable perceptions towards all learning experiences subscales except appropriate work load, which was negatively perceived (Mean score was 2.69 \pm 0.56 ). The most reported agreeable perceptions were satisfaction with OSCE (57.8\%), attending field training improved students' competences (55\%), improvement of consultation and communication skills of students by this FM module (52.3\%) and the assessment covered many ILOs totally (52.3\%).

Participants felt the presence of unwanted academic pressure on them, too many topics of syllabus, the unsatisfying of library resources for their needs, the heaviness of workload, and unhelpful portfolio guide.

Near half $(47.7 \%)$ of participants were satisfied with FM module. Most $(64.2 \%)$ of participants had negative perceptions with workload in FM module. There were no significant associations between participants' perceptions on learning experiences in FM module and their demographic and academic variables ( $P$ values based on Mann Whitney $U$ and Kruskal Wallis tests were $>0.05$ ).

Table 3 shows that there was strong positive correlation between participants' satisfaction and their perceptions towards good teaching and learning resources in FM module. Intellectual stimulation was positively correlated with learning resources. There was also strong positive correlation between generic skills and the intellectual motivation of FM module. The predictors of participants satisfaction towards FM module were learning resources (odds $=9.63$ ) and good teaching (odds $=7.624$ ) as shown in table 4 .

Participants' reported these advantages of FM module e.g. communication, history taking and consultation skills (35.8\%), training with real patients (20.2\%), e-learning website (15.6\%), qualification and learning styles of teaching staff and co-staff (14.7\%), learning how to manage common health problems at PHC settings (13.8\%) and performing clinical examinations (8.4\%). The most frequent participants' suggestions were availability of live lectures (37.6\%), adding more time for this module (16.5\%) and more clinical practice teaching (15.6\%) at PHC settings.

\section{Discussion}

A cross-sectional study was carried out to evaluate the fourth year medical students' perspectives on quality of FM education at FOM/SCU in the educational year 2017/2018 and to determine the associated factors of students' learning experiences in FM module.

In the present study, all of students' learning experiences in FM module were questionable perceived except workload was negatively perceived. More than half of participants positively perceived attending field training in improving their competences, FM module in improving their consultation and communication skills, assessment covering many ILOs and OSCE as a satisfying tool of assessment. 
Participants felt the presence of unwanted academic pressure on them, too many topics of syllabus, the unsatisfying of library resources for their needs, the heaviness of workload, and unhelpful portfolio guide.

Near half of participants were satisfied with FM module. The predictors of their satisfaction were learning resources and good teaching. Availability of frequent live lectures was the most frequent suggestion of participants.

\section{Participants' perceptions towards satisfaction with FM module}

In the current study, the student's overall satisfaction with the quality of FM module had a mean score of 3.34. This questionable perception does not conflict with the need for continues quality improvement of FM module to satisfy more students, even if FM module did not perceived negatively yet.

In Park's study, the mean scores of the fourth year students' overall satisfaction with FM at Dankook university hospital and a community hospital or clinic in Cheonan, Korea, were 4.5 and 4.3 on a 5-point scale, respectively [10]. Sound comparison could not be made due to different methodology of these studies.

\section{Participants' perceptions towards learning resources}

In the current study, participants" perception towards learning resources was the most predictor of participants' satisfaction, this might be due to training in PHC settings, availability of eLearning website in FM for fourth year medical students, and materials of FM module were clear, concise, relevant and up to date, which had positive impacts on their learning and assessment.

Training in PHC settings might able participants to become health provider dealing with the common health problems among children and women in the community, health educator, professional, member of PHC member and an active learner. E-Learning website included interactive MCQs, lectures, learning videos, quizzes, assignments, interaction with staff/co-staff and students and orientations about OSCE, clinical exam and written exam. The structured assessment of this eLearning was out of this research scope.

Despite majority of participants positively perceived improvement of their competencies by training in $\mathrm{PHC}$ setting, the mean score of participants' perceptions toward this item was questionable in the present study. This finding was consistent with finding in another study among pregraduate medical students enrolled in FM rotation at Wuppertal PHC and Research Center in Wuppertal, Germany [11].

Participants had negative perceptions towards appropriability of traditional library resources for their needs (the mean score was 2.76), this might a result of using information technology in education and availability of lectures' material helping their learning. This finding is consistent with Salama and NourEldein finding where students reported perceptions with mean score of 2.66 [5]. These findings reflected shifts in education methods and the impact of computer technology. 
Portfolio is evidence that students mastered the required skills and achieved the objectives of FM. It included ILOs, personal learning plan, list of cases during FM round, the required practical and clinical skills to be fulfilled and signed by trainers at the end of FM round, two evidence-based medicine case studies, professionalism evaluation form, self-reflection on their learning and scoring criteria of FM fourth year portfolio. It seemed that students perceptions with portfolio as hardworking paper takes time outweighs its importance so, their perceptions were negative in the present study.

\section{Participants' perceptions towards good teaching}

Good teaching was the second predictor of participants' satisfaction, this might be due to tutors at field training and the designers of the eLearning website worked hard to make the FM subjects interesting. Trainers at field work were extremely good at discussing health problems, which students encountered at PHC settings, made a real effort to understand any difficulties they had during learning and with PHC team or clients and gave helpful oral feedback to students on their progress and document relevant feedback on their portfolio.

\section{Participants' perceptions towards generic skills}

In the present study, majority of participants had positive perceptions about improvement of their consultation and communication skills after attending FM module. This result was consistent with a result of a systematic review on impact of FM clerkships in undergraduate medical education [4].

Participants were skeptical about sharping of their analytic skills by FM module in the present study. Kavukcu et al found medical students were doubtful about well-developed problem solving skills after FM rotation [11] and authors considered that not bad but need improvement.

\section{Participants' perceptions towards intellectual motivation}

In the current study, participants reported questionable perceptions about FM module's education as stimulating. In another study in Germany, students perceived positively teaching FM as often stimulating [11]. This difference might be the result of differences in the environments of learning.

\section{Participants' perceptions towards clear outcomes and standards}

In the present study, participants had questionable perceptions with clear idea of where they were going and what there were expected. This might be the result of negative participants' perceptions with usefulness of portfolio guide and they spend relatively short time in studying FM compared with others module in primary care course. This finding was congruent with Kavukcu et al.'s finding [11].

\section{Participants' perceptions towards appropriate assessment}

Assessment in FM module included varieties of assessing methods. In the current study, the' mean score of participants' perceptions towards satisfaction with OSCE was the higher than others learning experiences' mean scores; this finding might be due to OSCE exam was consisted of 12 stations, covering 
wide range of ILOs, with adequate time of stations and clear candidate instructions, having educational impacts on them and extensive explanations about what would be covered in the OSCE were provided to students via eLearning website.

In another study, the final year medical students valued the OSCE as a tool of assessment in FM course at FOM, Qassim University in Kingdom of Saudi Arabia with mean score of 0.33 [12]. Direct comparison with this study was difficult due to different methodology of these studies.

\section{Participants' perceptions towards appropriate work load}

In the present study, the participants' were overload with FM module; this might be because of their perceptions of covering many topics in syllabus, traveling to another governorate in Suez Canal region for learning stressed them in addition to they need relative light workload in FM module to spend more time of learning in others pediatrics and gynecology modules, which had a priority from their perspectives.

Kavukcu et al found that participants positively perceived with enjoyment outweigh the stress of FM course [11]. In the present study, participants felt presence of too much unwanted academic pressure on them. This difference related to different learning environments.

\section{Students' opinion about advantages of FM module:}

In the present study, participants reported advantages of FM module e.g. improvement in their communication, history taking and consultation skills and learning how to manage common health problems at PHC settings. These advantages were reported in previous studies with different percentages due to different learning environments [13-15].

\section{Student suggestions for improving quality of FM module:}

In the current study, participants suggested more live lectures because of they didn't receive any live lectures during FM module. They also recommended adding more time for the module and more time for clinical practice teaching at PHC settings. Cooper reported similar suggestions were; the attachment should be longer, greater involvement of the student, and more teaching of practical skills [13].

\section{Associated factors with participants' learning experiences}

There were no significant associations between satisfaction and learning sociodemographic variables in the present study. This was incongruent with Salama and Nour-Eldein finding where there was statistically significant relationship between satisfaction with FM module and female gender [5].

Generic skills were strongly positive correlated with intellectual motivation Participants' satisfaction was predicted by learning resources and good teaching. Studies into associated factors or predictors of quality of undergraduate family medicine education seem to be scare, so it is difficult to make sound comparison.

\section{Limitations of the current study:}


The generalization of this study's results is limited by lack of randomization. The study is not designed to address cause effect relationship of teaching quality in FM; it can only suggest association for further research.

\section{Conclusion}

Near half of the students were satisfied with the quality of the FM module. There was no significant association between students' demographic and academic variables and their perspectives with quality of FM module. Learning resources and good teaching were predictors of quality of undergraduate FM education. Availability of live lectures, adding more time for the module, and more clinical practice teaching at PHC settings were suggested to improve the quality of FM module.

\section{Abbreviations}

CBE: Community-based education

CEQ: Course experience questionnaire

FM: Family medicine

FMD: Family Medicine department

FOM/SCU: Faculty of medicine, Suez Canal University

ILOs: Intended learning outcomes

MCQs: Multiple choice questions

MEQs: Modified essay questions

MOHP: Ministry of Health and Population

OSCE: Objective structured clinical examination

PBL: Problem-based learning

PHC: Primary health care

SPSS: Statistical package for social sciences

UMEQ: Undergraduate Module Experience Questionnaire

\section{Declarations}

Ethics approval and consent to participate 
The study was approved by the research ethics committee of Faculty of Medicine, Suez Canal University prior conducting this study and its approval number was 3527. Consent was obtained from the Vice Dean for students' affairs and education of FOM/SCU for questioning the students. The coordinator of the phase 3 was contacted to inform him/her about the study. Written informed consent was obtained from all the participants before collecting any data via emails by the main author.

\section{Consent to publish}

A written informed consent for publication was obtained from all participants.

\section{Availability of data and materials}

The datasets used and/or analysed during the current study are available from the corresponding author on reasonable request.

\section{Competing interests}

The authors declare that they have no competing interests.

\section{Funding}

There was no funding for this research.

\section{Authors' contributions}

SA designed the study, implemented the study, analyzed the data and revised the manuscript.

HA contributed to the study design, supervised implementation of the study, analyzed the data, contributed to interpretation of study findings, drafted and revised the manuscript.

HN contributed to the study design, supervised implementation of the study, contributed to interpretation of study findings, and critically reviewed the manuscript. All authors read and approved the final manuscript.

\section{Acknowledgments}

Deepest thanks extended to fourth year medical students, FOM/SCU in academic year 2017/2018, who participated in this study.

\section{References}

1. Hosny S, Ghaly M, Boelen C. Is our medical school socially accountable? The case of Faculty of Medicine, Suez Canal University. Med Teach. 2015;37(1):47-55. doi: 10.3109/0142159X.2015.1006600. Epub 2015 Feb 4. 
2. Joshi MA. Quality assurance in medical education. Indian J Pharmacol. 2012;44(3):285-7. doi: 10.4103/0253-7613.96295.

3. Thien LM, Ong MY. The applicability of course experience questionnaire for a Malaysian university context. Qual Assur Edu. 2016;24(1):41-55. https://doi.org/10.1108/QAE-08-2014-0041

4. Turkeshi E, Michels NR, Hendrickx K, Remmen R. Impact of family medicine clerkships in undergraduate medical education: a systematic review. BMJ open. 2015;5(8):e008265. doi: 10.1136/bmjopen-2015-008265.

5. Salama HM, Nour-Eldein H. Final year medical students' satisfaction with clinical education and family medicine module. Suez Canal University. Egypt. J Contemp Med Edu. 2016;4(3):113-119. doi: $10.5455 / \mathrm{jcme} .20160614032416$.

6. AlKot MM, Gouda MA, KhalafAllah MT, Zahran MS, Kallaf MM, Zayed AM. Family medicine in Egypt from medical students' perspective: a nationwide survey. Teach Learn Med. 2015;27(3):264-273. doi: 10.1080/10401334.2015.1044654.

7. Hosny S, Kamel MH, El-Wazir Y, Gilbert J. Integrating interprofessional education in community-based learning activities: case study. Med Teach. 2013;35(1):68-73.

8. Broomfield D, Bligh J. An evaluation of the 'short form' course experience questionnaire with medical students. Med Educ. 1998;32(4):367-369. doi: 10.3109/0142159X.2013.765550.

9. McInnis C, Griffin P, James R, Coates H. Development of the course experience questionnaire (CEQ). Canberra: Department of Education, Training and Youth Affairs; 2001.

http://citeseerx.ist.psu.edu/viewdoc/download?doi=10.1.1.623.6651\&rep=rep1\&type=pdf, accessed 15 September 2018.

10. Park EW. Comparison of Medical Students' Satisfaction with Family Medicine Clerkships between University Hospitals and Community Hospitals or Clinics. Korean J Fam Med. 2016;37(6):340-345. doi: 10.4082/kjfm.2016.37.6.340. PMCID: PMC5122666

11. Kavukcu E, Burgazli KM, Akdeniz M, Bilgili P, Öner M, Koparan S, et al. Family medicine and sports medicine students' perceptions of their educational environment at a primary health care center in Germany: using the DREEM questionnaire. Postgrad Med. 2012;124(5):143-150. doi:

10.3810/pgm.2012.09.2585.

12. Al-Mohaimeed A, Midhet F, Barrimah I, Khan NZ, Sharaf FK, Alnohair S. Students' perceptions about the family medicine course in Qassim, Saudi Arabia. Med Teach. 2014;36(1):S49-S54. doi: 10.3109/0142159X.2014.886010.

13. Cooper CW. Medical students' perceptions of an undergraduate general practice preceptorship. Fam Prac. 1992;9(3):323-329. doi: 10.1093/fampra/9.3.323. 
14. Lloyd MH, Rosenthal JJ. The contribution of general practice to medical education: expectations and fulfillment. Med Educ. 1992;26(6):488-496. PMID: 1461167. https://doi.org/10.1111/j.1365-

2923.1992.tb00211.x

15. Švab I, Petek-Šter M. Long-term evaluation of undergraduate family medicine curriculum in Slovenia. Srp Arh Celok Lek. 2008;136(5-6):274-279. doi: 10.2298/SARH0806274S.

\section{Tables}

Table 1. Characteristics of the study sample

\begin{tabular}{|c|c|c|}
\hline Variables & $\mathrm{n}=109$ & $\%$ \\
\hline \multicolumn{3}{|l|}{ Gender } \\
\hline Male & 37 & 34 \\
\hline Female & 72 & 66 \\
\hline \multicolumn{3}{|l|}{ Marital status } \\
\hline Single & 108 & 99.08 \\
\hline Married & 1 & 0.92 \\
\hline \multicolumn{3}{|c|}{ Perceived family income } \\
\hline Sufficient & 100 & 91.74 \\
\hline Insufficient & 9 & 8.26 \\
\hline \multicolumn{3}{|l|}{ Last academic grade } \\
\hline Acceptable & 3 & 2.75 \\
\hline Good & 18 & 16.51 \\
\hline Very good & 50 & 45.87 \\
\hline Excellent & 38 & 34.86 \\
\hline
\end{tabular}

Table 2. Frequency distribution of participants' perceptions towards learning experiences in family medicine module 


\section{Variables}

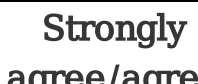

agree/agree
No

opinion

\section{Clear Outcomes \& standards Subscale}

n

$\%$

n

$\%$

$\%$

$\underset{\mathrm{n}}{\mathrm{disag}}$

Strongly

disag

$\%$

I had a clear idea of where I was going and what was expected of me

It was always easy to know the standard of assignments expected

The assessment is totally different from the ILOs*

\section{Good Teaching Subscale}

$\begin{array}{lll}43 & 39.4 \quad 50 \quad 45 .\end{array}$

$38 \quad 34.9 \quad 50$

$23 \quad 21.1$

Teaching staff/co-staff normally give me helpful

feedback on my progress

Teaching staff/co-staff made a real effort to understand any difficulties I had

Teaching staff/co-staff in this module is extremely good at explaining things

Teaching staff/co-staff worked hard to make the subjects interesting

Teaching staff/co-staff put a lot of time into comments (orally/writing) on my work

\section{Appropriate Work load Subscale}

$\begin{array}{lllll}50 & 45.9 & 34 & 31.2 & 25\end{array}$

$45.9 \quad 16$

$45.9 \quad 21$

46

46

42.2

$47 \quad 43.1 \quad 49$

48

44.0

43

32

29.4

$29.4 \quad 57$

84

Mean

score \pm

SD

$3.19 \pm$

0.61

$24 \pm$ 0.83

$3.15 \pm$ 0.82

$3.17 \pm$ 0.87

$3.3 \pm$

0.75

$22.9 \quad 3.3 \pm$

0.99

$17.4 \quad 3.31 \pm$

0.93

$3.41 \pm$ 0.92

$3.36 \pm$ 0.97

$3.14 \pm$ 0.81

$2.69 \pm$ 0.56

There is a lot of unwanted academic pressure on me as $\quad \begin{array}{lllllll}67 & 61.5 & 24 & 22.0 & 18 & 16.5 & 2.46 \pm\end{array}$ a student*

The workload in this module is too heavy* 41

I was generally given enough time to understand the 34

things I had learnt

It seems to me that the syllabus tries to cover too 56

56

51.4

37.6

4238

$38.5 \quad 26$

0.96

$23.9 \quad 2.82 \pm$

0.97

many topics*

\section{Appropriate Assessment Subscale}

$\begin{array}{lllll}34 & 31.2 & 46 & 42.2 & 29\end{array}$

Totally, assessment covered many ILOs

$\begin{array}{lll}57 & 52.3 \quad 35\end{array}$

MCQs were very difficult* 36

$43.1 \quad 6$

29

26.6

$3.01 \pm$ 0.98

I am satisfied with OSCE

I am satisfied with OSCE

36

$33.0 \quad 48$

63

Teaching staff/co-staff asked a lot of irrelevant 34

questions during clinical exam*

The content and time of the MEQs were appropriate

$63 \quad 57.8 \quad 30 \quad 27.5 \quad 16$

$5.5 \quad 2.47 \pm$

0.72

$3.23 \pm$

0.59

$\begin{array}{ccccccc}34 & 31.2 & 36 & 33.0 & 39 & 35.8 & \begin{array}{c}3.1 \pm \\ 0.99\end{array} \\ 44 & 40.4 & 46 & 42.2 & 19 & 17.4 & \begin{array}{c}3.3 \pm \\ 0.87\end{array} \\ \end{array}$

\section{Generic Skills Subscale}

This module has helped me develop my ability to work 52

$\begin{array}{lllll}52 & 47.7 & 33 & 30.3 & 24\end{array}$

22.0

0.79

as part of a group 
This module has helped sharpen my analytic skills

Since doing this module, I feel more confident about tackling problems

This module has improved my consultation and communication skills

\begin{tabular}{ccccccc}
48 & 44.0 & 38 & 34.9 & 23 & 21.1 & $\begin{array}{c}3.23 \pm \\
0.94\end{array}$ \\
\hline 38 & 34.9 & 48 & 44.0 & 23 & 21.1 & $\begin{array}{c}3.14 \pm \\
0.87\end{array}$ \\
\hline 57 & 52.3 & 40 & 36.7 & 12 & 11.0 & $\begin{array}{c}3.45 \pm \\
0.84\end{array}$ \\
\hline
\end{tabular}

* Reverse-coded Likert items

Table 2. Continued

\begin{tabular}{|c|c|c|c|c|c|c|c|}
\hline \multirow[t]{2}{*}{ Variables } & \multicolumn{2}{|c|}{$\begin{array}{c}\text { Strongly } \\
\text { agree/agree }\end{array}$} & \multicolumn{2}{|c|}{$\begin{array}{l}\text { No } \\
\text { opinion }\end{array}$} & \multicolumn{2}{|c|}{$\begin{array}{c}\text { Strongly } \\
\text { disagree/disagree }\end{array}$} & \multirow{2}{*}{$\begin{array}{c}\text { Mean } \\
\text { score } \pm \\
\text { SD }\end{array}$} \\
\hline & $\mathrm{n}$ & $\%$ & $\mathrm{n}$ & $\%$ & $\mathrm{n}$ & $\%$ & \\
\hline Intellectual Motivation Subscale & & & & & & & $\begin{array}{c}3.16 \pm \\
0.79\end{array}$ \\
\hline This module is intellectually stimulating & 40 & 36.7 & 51 & 46.8 & 18 & 16.5 & $\begin{array}{c}3.21 \pm \\
0.83\end{array}$ \\
\hline I have found this module motivating & 42 & 38.5 & 40 & 36.7 & 27 & 24.8 & $\begin{array}{c}3.16 \pm \\
0.92\end{array}$ \\
\hline $\begin{array}{l}\text { This module has stimulated my interest in the field of } \\
\text { study (Family medicine) }\end{array}$ & 37 & 33.9 & 42 & 38.5 & 30 & 27.5 & $\begin{array}{c}3.1 \pm \\
0.97\end{array}$ \\
\hline Learning Resources Subscale & & & & & & & $\begin{array}{c}3.17 \pm \\
0.65\end{array}$ \\
\hline Attending field training improved my competences & 60 & 55.0 & 38 & 34.9 & 11 & 10.1 & $\begin{array}{c}3.51 \pm \\
0.86\end{array}$ \\
\hline Portfolio guide was very helpful & 41 & 37.6 & 35 & 32.1 & 33 & 30.3 & $\begin{array}{c}2.97 \pm \\
1.1\end{array}$ \\
\hline $\begin{array}{l}\text { The used information technology in teaching and } \\
\text { learning was effective }\end{array}$ & 53 & 48.6 & 37 & 33.9 & 19 & 17.4 & $\begin{array}{c}3.33 \pm \\
1.1\end{array}$ \\
\hline Lectures were available to help me learn & 53 & 48.6 & 30 & 27.5 & 26 & 23.9 & $\begin{array}{c}3.18 \pm \\
1.13\end{array}$ \\
\hline The library resources were appropriate for my needs & 24 & 22.0 & 46 & 42.2 & 39 & 35.8 & $\begin{array}{c}2.76 \pm \\
0.99\end{array}$ \\
\hline The study materials were clear and concise & 35 & 32.1 & 53 & 48.6 & 21 & 19.3 & $\begin{array}{c}3.13 \pm \\
0.88\end{array}$ \\
\hline Module materials were relevant and up to date & 44 & 40.4 & 49 & 45.0 & 16 & 14.7 & $\begin{array}{c}3.31 \pm \\
0.92\end{array}$ \\
\hline Overall Satisfaction with module & & & & & & & $\begin{array}{c}3.34 \pm \\
0.87\end{array}$ \\
\hline Overall, I am satisfied with the quality of this module & 52 & 47.7 & 38 & 34.9 & 19 & 17.4 & $\begin{array}{c}3.34 \pm \\
0.87\end{array}$ \\
\hline
\end{tabular}


Table 3. Correlation between subscales of UMEQ

\begin{tabular}{|c|c|c|c|c|c|c|c|}
\hline Subscales & $\begin{array}{l}\text { ClearOutcomes \& } \\
\text { standards }\end{array}$ & $\begin{array}{c}\text { Good } \\
\text { Teaching }\end{array}$ & $\begin{array}{l}\text { Appropriate } \\
\text { Workload }\end{array}$ & $\begin{array}{l}\text { Appropriate } \\
\text { Assessment }\end{array}$ & $\begin{array}{l}\text { Generic } \\
\text { Skills }\end{array}$ & $\begin{array}{l}\text { Intellectual } \\
\text { Motivation }\end{array}$ & $\begin{array}{l}\text { Learning } \\
\text { Resources }\end{array}$ \\
\hline $\begin{array}{l}\text { Good Teaching } \\
\text { Appropriate } \\
\text { Work load }\end{array}$ & $\begin{array}{c}0.319 * * \\
0.197 *\end{array}$ & 0.172 & & & & & \\
\hline $\begin{array}{l}\text { Appropriate } \\
\text { Assessment }\end{array}$ & $0.350 * *$ & $0.375^{* *}$ & $0.207 *$ & & & & \\
\hline Generic Skills & $0.356^{* *}$ & $0.510 * *$ & $0.209 *$ & $0.390 * *$ & & & \\
\hline $\begin{array}{l}\text { Intellectual } \\
\text { Motivation }\end{array}$ & $0.346^{* *}$ & $0.496 * *$ & $0.190 *$ & $0.297 * *$ & $0.655^{* *}$ & & \\
\hline $\begin{array}{l}\text { Learning } \\
\text { Resources }\end{array}$ & $0.539 * *$ & $0.571 * *$ & 0.144 & $0.387 * *$ & $0.520 * *$ & $0.628 * *$ & \\
\hline $\begin{array}{l}\text { Overall } \\
\text { Satisfaction }\end{array}$ & $0.407 * *$ & $0.618^{* *}$ & $0.263 * *$ & $0.383 * *$ & $0.510 * *$ & $0.469 * *$ & $0.662 * *$ \\
\hline
\end{tabular}

$\mathrm{n}=109$; **correlation is significant at 0.01 level; *correlation is significant at 0.05 (2-tailed).

Spearman's rho test was used to assess correlation between subscales

Table 4. Binary logistic regression analysis for predictors of participants' satisfaction towards family medicine module

\begin{tabular}{lccccccc}
\hline & B & S.E. & Wald & Sig. & Exp (B) & 95 \% C.I. for EXP (B) \\
& & & & & & Lower & Upper \\
\hline Clear Outcomes and standards & 0.639 & 0.650 & 0.966 & 0.326 & 1.894 & 0.530 & 6.771 \\
Good Teaching & 2.034 & 0.634 & 10.296 & 0.001 & $7.642^{*}$ & 2.207 & 26.468 \\
\hline Appropriate Work load & 0.278 & 0.615 & 0.204 & 0.651 & 1.320 & 0.396 & 4.404 \\
\hline Appropriate Assessment & 0.822 & 0.610 & 1.815 & 0.178 & 2.276 & 0.688 & 7.528 \\
\hline Generic Skills & 0.448 & 0.599 & 0.559 & 0.455 & 1.564 & 0.484 & 5.057 \\
\hline Intellectual Motivation & $-.523-$ & 0.615 & 0.722 & 0.395 & 0.593 & 0.178 & 1.980 \\
\hline Learning Resources & 2.265 & 0.796 & 8.105 & 0.004 & $9.633^{*}$ & 2.025 & 45.818 \\
\hline Constant & $-19.346-$ & 3.918 & 24.386 & 0.000 & 0.000 & & \\
\hline
\end{tabular}

Mean scores of independent variables were used in this analysis

Omnibus Tests of Model Coefficients: Chi-square was 73.074 \& Statistically significant at $p<0.001$ )

Model Summary: -2 Log likelihood was 77.803, Cox \& Snell R Square was 0.488 \& Nagelkerke R Square was 0.652

*Statistically significant at $p<0.05$

\section{Supplementary Files}


This is a list of supplementary files associated with this preprint. Click to download.

- supplement1.xlsx

- supplement2.docx

- supplement3.xlsx

- supplement4.doc

- supplement5.doc 